\title{
A study on the wire drawing of TiNi shape memory alloys
}

\author{
S.K. Wu $u^{\mathrm{a}}$, H.C. Lin ${ }^{\mathrm{b}}$, Y.C. Yen ${ }^{\mathrm{c}}$ \\ anstitute of Materials Science and Engineering. National Taiwan University, Taipei, Taiwan 106, People's Republic of China \\ 'Department of Materials Science, Feng-Chia University, Taichung, Taiwan 400, People's Republic of China \\ 'Department of Mechanical Engineering, Chin-Ming College, Miaoli, Taivan 351, Republic of China
}

\begin{abstract}
Drawn wires of TiNi shape memory alloys (SMAs) have been studied systematically using DSC, microhardness, SEM and tensile tests. Severe work hardening during the drawing process is observed and hence interannealing is necessary. Multi-pass drawing around the Ms temperature is recommended. The defects induced by cold drawing depress martensitic transformation but promote the R-phase transformation. Defect recovery and recrystallization during interannealing are responsible for the decrease of drawing stress. At the same time, surface oxide film thickness is another important factor related to drawing stress. A thin surface oxide film can be used as a lubricant during the drawing process, however, thick oxide films tend to exhibit cracks and spalling which decrease the drawing surface quality, shape memory effect and pseudoelasticity of TiNi SMAs. MoS 2 is shown to be an effective lubricant for the wire drawing of TiNi SMAs.
\end{abstract}

Keywords: Shape memory alloys; Annealing; Pseudoelasticity; Lubricants

\section{Introduction}

TiNi alloys are an important class of shape memory alloys (SMAs). They exhibit not only the shape memory effect (SME) [1], but also unusual pseudoelasticity $[2,3]$ and high damping capacities $[4,5]$. These properties along with their superior ductility, strength, fatigue and corrosion resistance, have resulted in many applications, among which use in the manufacture of wire forms figures prominently. In wire applications, TiNi SMAs are usually produced as wire springs, hollow wires and various nonregular shapes [6-9]. Recently, ultra-fine or hollow TiNi wires have been developed and have shown improved SME which is promoted by their higher cooling rates during the cooling process. There are many promising applications for these wires in products such as microactuators and microsprings. Therefore, the understanding of drawn wire properties is important for TiNi SMA applications.

As mentioned above, TiNi wire products have many potential applications, however, the roadblocks to their development are caused by difficulties in the manufacturing process. It is well known that TiNi alloys can be tensile deformed in a ductile manner to more than $50 \%$ strain prior to fracture [1], but severe strain hardening accompanied by cold-working and wire-drawing hin- ders their workability. To overcome this difficulty, some special wire drawing processes have been developed such as the dieless drawing [10] and clad-chip extrusion [11]. However, even these new processes have some technical limits $[10,11]$. As we approach a solution to these problems, an understanding of the intrinsic wire drawing properties of TiNi SMAs becomes important. To the best of our knowledge, however, no systematic investigation of the drawing properties of TiNi SMAs has been reported, although some papers have reported the effects of cold work and annealing on transformation temperatures $[2,3,12-14]$. In the present study, we aim to systematically investigate the wire drawing properties of TiNi SMAs under various drawing conditions. The surface oxide film and lubricants used in the drawing process are also discussed.

\section{Experimental procedure}

\subsection{Materials preparation and the drawing process}

A conventional tungsten arc-melting technique was employed to prepare $\mathrm{Ti}_{50} \mathrm{Ni}_{50}, \mathrm{Ti}_{49.7} \mathrm{Ni}_{50.3}, \mathrm{Ti}_{49} \mathrm{Ni}_{51}$ alloys. Titanium (purity, 99.7\%) and nickel (purity, $99.98 \%$ totalling $100 \mathrm{~g}$, were melted and remelted at 
least six times in an argon atmosphere. The weight loss during melting was negligibly small. The as-melted buttons were homogenized at $1050^{\circ} \mathrm{C}$ for $72 \mathrm{~h}$ and then hot-rolled at $850{ }^{\circ} \mathrm{C}$ to form plates $1.25 \mathrm{~mm}$ thick. Specimens for wire drawing $(\phi 1.2 \mathrm{~mm} \times 300 \mathrm{~mm})$ were carefully cut and ground from these plates. Before wire drawing, residual stress was removed and a thin oxide film was created by annealing for $10 \mathrm{~min}$ at $550^{\circ} \mathrm{C}$. The wires were drawn without the use of lubricants except for the process described in Section 3.4 in which one of the lubricants $\mathrm{MoS}_{2}$, oil, or soap was used during the drawing process.

The drawing machine and the wire head machine have been illustrated in a previous paper [15]. Singlepass or multi-pass drawing with or without lubricant can be conducted at a controlled speed ranging from 5-20 $\mathrm{m} \mathrm{min}^{-1}$. In the single-pass process, the set crosssection reduction is carried out by a single pass through one die. In the multi-pass process, the desirable cross section is obtained by multiple passes through several dies. Tungsten carbide dies are used for wire diameters $\gtrsim 100 \mu \mathrm{m}$ and diamond dies are used for diameters $<100 \mu \mathrm{m}$. The drawing force during the wire drawing can be recorded in-situ by an S-type Load Cell.

\subsection{Measurement techniques and equipment}

The properties of TiNi SMAs drawn wire, including transformation temperatures, mechanical properties and some other interesting aspects were studied by differential scanning calorimetry (DSC), Vickers microhardness testing and tensile testing. DSC was conducted using a DuPont 9900 thermal analyzer equipped with a quantitative scanning system 910 DSC cell to control the heating and cooling rates on samples encapsulated in an aluminum pan. Test temperatures ranged from $-60{ }^{\circ} \mathrm{C}$ to $+100{ }^{\circ} \mathrm{C}$ with a heating/cooling rate of $10^{\circ} \mathrm{C} \mathrm{min}-1$. The heat of transformation, $\Delta H$, was automatically calculated from the area under the DSC peak with the equipment software packages. Hardness testing was done using a Vickers microhardness tester with a $300 \mathrm{~g}$ load at room temperature. For each specimen, the hardness value, $H_{\mathrm{v}}$, was averaged from five test readings. Tensile tests were carried out using an UTM-3-500 type tensile tester with a strain rate of 5 $\mathrm{mm} \mathrm{min}^{-1}$.

\section{Results and discussion}

\subsection{The wire drawing stress of TiNi SMAs}

Fig. 1 (a)-(c) show drawing stress and specimen hardness vs. the degree of cold work for the $\mathrm{Ti}_{49.7} \mathrm{Ni}_{50.3}$ alloy tested at room temperature. Here the drawing stress is defined as the drawing force divided by wire cross-sectional area and the degree of cold work is defined as the percent reduction in the wire cross-sectional area. In Fig. 1, the drawing stress and hardness are found to increase sharply with increasing degrees of cold work. These results reflect the severe work hardening that occurs in TiNi SMAs and that interannealing is necessary during the drawing process. One feature shown in Fig. 1(a) and (b) is the large difference in drawing stress needed to obtain the same degree of cold work in between single-pass and multi-pass specimens. Obviously, the occurrence of this feature is because the strain rate of the single-pass process is larger than that of the multi-pass process for the same total cold-working. Another important feature pertaining to the drawing process is the deformation homogeneity across the wire section. As shown in Fig. 2, for the drawn $\mathrm{Ti}_{50} \mathrm{Ni}_{50}$ wires with the same degree of cold work, the two-pass drawing shows a more homogeneous hardness profile across the wire section than the single-pass drawing. This indicates that the multi-pass drawing exhibits a better deformation homogeneity. Thus, a multi-pass drawing is more suitable than a single-pass one to draw TiNi wires.

Fig. 3 shows the experimental results of the drawing stress vs. drawing temperature for as-annealed $\mathrm{Ti}_{49.7} \mathrm{Ni}_{50.3}$ samples. The DSC result shows that this alloy has a start temperature of martensitic transformation, $M_{\mathrm{s}}$, at $23{ }^{\circ} \mathrm{C}$, and a finish temperature of martensitic transformation, $M_{\mathrm{f}}$, at $0{ }^{\circ} \mathrm{C}$. In Fig. 3, the drawing stress has a minimum at about $25{ }^{\circ} \mathrm{C}$. This phenomenon is very similar to TiNi bulk specimens [16] in

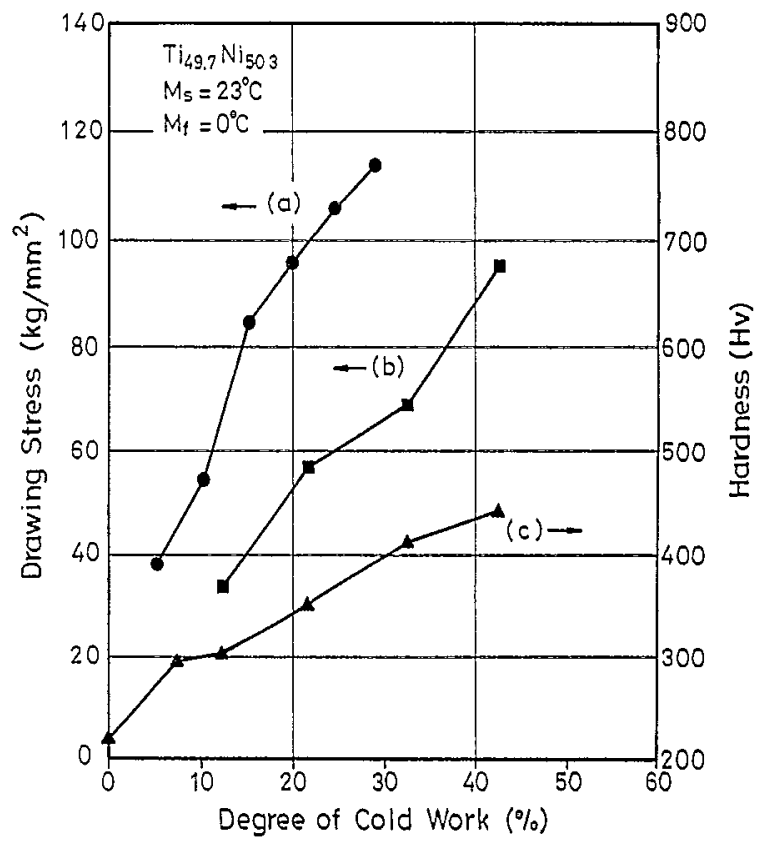

Fig. 1. (a) The drawing stress of single-pass wire, (b) the drawing stress of multi-pass wire, (c) specimen hardness Hv, vs. the degree of cold work at room temperature for $\mathrm{Ti}_{49.7} \mathrm{Ni}_{50.3}$ alloy. 


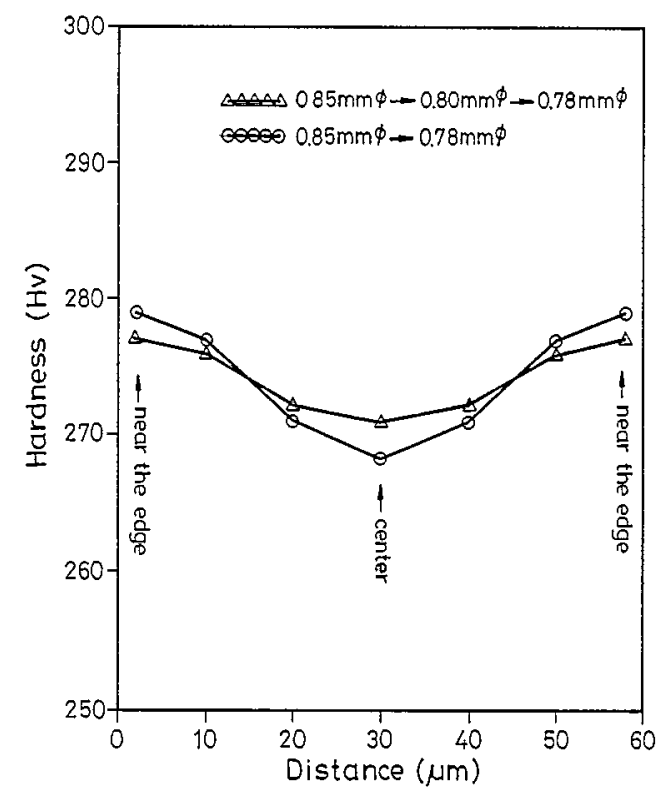

Fig. 2. The hardness curves across the wire section for $\mathrm{Ti}_{50} \mathrm{Ni}_{50}$ wires drawn from $0.85 \mathrm{~mm} \phi$ to $0.78 \mathrm{~mm} \phi$.

which the tensile yield stress exhibits a minimum value around the Ms temperature. The curve minima in Fig. 3 shows that the wire drawing of TiNi SMAs will require lower stresses when carried out near the $M_{\mathrm{s}}$ temperature. This feature is closely related to the occurrence of the "soft" mode which is associated with the martenstic transformation of TiNi SMAs [17,18]. Therefore, it is recommended that wire drawing processes of TiNi SMAs be performed at or near $M_{\mathrm{s}}$ temperature.

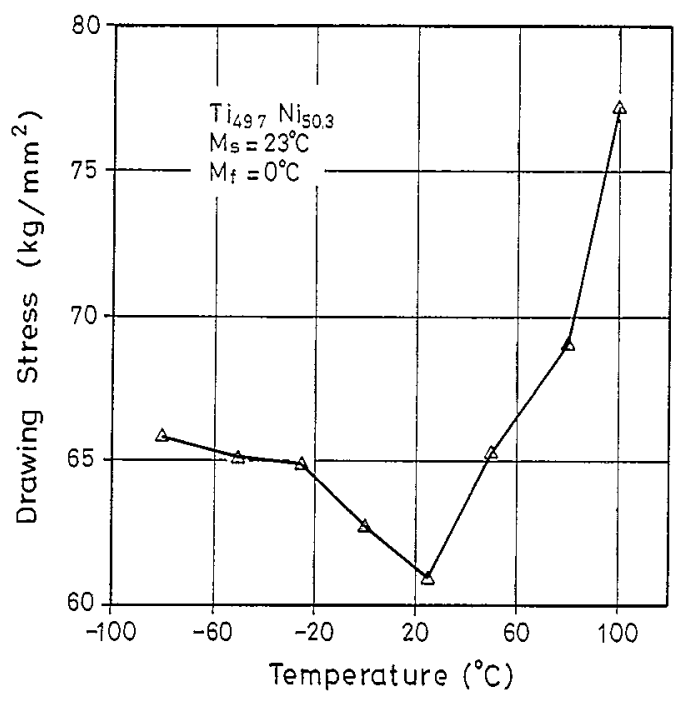

Fig. 3. The drawing stress vs. drawing temperature for the as-annealed $\mathrm{Ti}_{49}{ }_{7} \mathrm{Ni}_{503}$ wire.

\subsection{The effects of interannealing on the transformation temperature and drawing stress}

As mentioned above, the work hardening of TiNi SMAs is quite severe and interannealing during the drawing process is necessary. Both the annealing temperature and time are important parameters which can affect transformation temperatures and drawing stress. Fig. 4(a)-(h) show some typical DSC curves for drawn $\mathrm{Ti}_{50} \mathrm{Ni}_{50}$ wires which have been $26.5 \%$ cold-worked, and then annealed at various temperatures and time periods. Cold-worked specimens of other degrees have produced similar results to those shown in Fig. 4 and therefore are omitted here. In Fig. 4, peaks $\mathrm{R}^{*}, \mathrm{M}^{*}$ and $A^{*}$ indicate the transformations of parent $B 2$ phase into rhombohedral premartensite R-phase, R-phase into martensite $\mathrm{B} 19^{\prime}$ phase and $\mathrm{B} 19^{\prime}$ phase into $\mathrm{B} 2$ phase, respectively. At the same time, in Fig. 4(a)-(g), one can find that the R-phase transformation appears prior to the martensitic transformation; therefore, the R-phase transformation can be induced by wire drawing followed by $300-600{ }^{\circ} \mathrm{C}$ interannealing. The residual internal stress induced by cold-working defects is considered to be responsible for the R-phase transformation [21,22]. In order to understand the effects of cold drawing and interannealing on the transformation temperatures, the experimental results of $\mathrm{R}^{*}$ and $\mathrm{M}^{*}$ vs. annealing time for different annealing temperatures are plotted in Fig. 5. In Fig. 5, under the same degree of cold work, $\mathrm{R}^{*}$ slowly decreases, but $\mathrm{M}^{*}$ quickly increases with increasing annealing time. This shows that the defects induced by cold drawing depress the martensitic transformation but promote the R-phase transformation. During the annealing, these defects continuously die out, and the residual internal stress also decreases simultaneously. Therefore, the effects of cold drawing on transformation temperatures decrease with increasing annealing time. This leads to the feature that $\mathrm{R}^{*}$ temperature decreases, while $\mathrm{M}^{*}$ temperature increases with the increasing annealing time, eventually merging $R^{*}$ and $M^{*}$ temperatures. As shown in Fig. 4(h) and 5, this merging time is about $30 \mathrm{~min}$ for 600 ${ }^{\circ} \mathrm{C}$ annealing, and about $70 \mathrm{~min}$ for $550^{\circ} \mathrm{C}$ annealing.

Fig. 6 shows the drawing stress at $10.43 \%$ cold working for the $26.5 \%$ pre-drawn $\mathrm{Ti}_{50} \mathrm{Ni}_{50}$ specimens interannealed at various temperatures and time periods. The drawing stress for specimens interannealed at higher temperatures is found to be lower. Defect recovery and recrystallization during the interannealing process are responsible for this feature. Drawing stress decreases to a low value with a $10 \mathrm{~min}$ annealing treatment at $600{ }^{\circ} \mathrm{C}$. However, the $300^{\circ} \mathrm{C} \times 10-60 \mathrm{~min}$ interannealing has no effect on the drawing stress because defect recovery and recrystallization are almost negligible. 

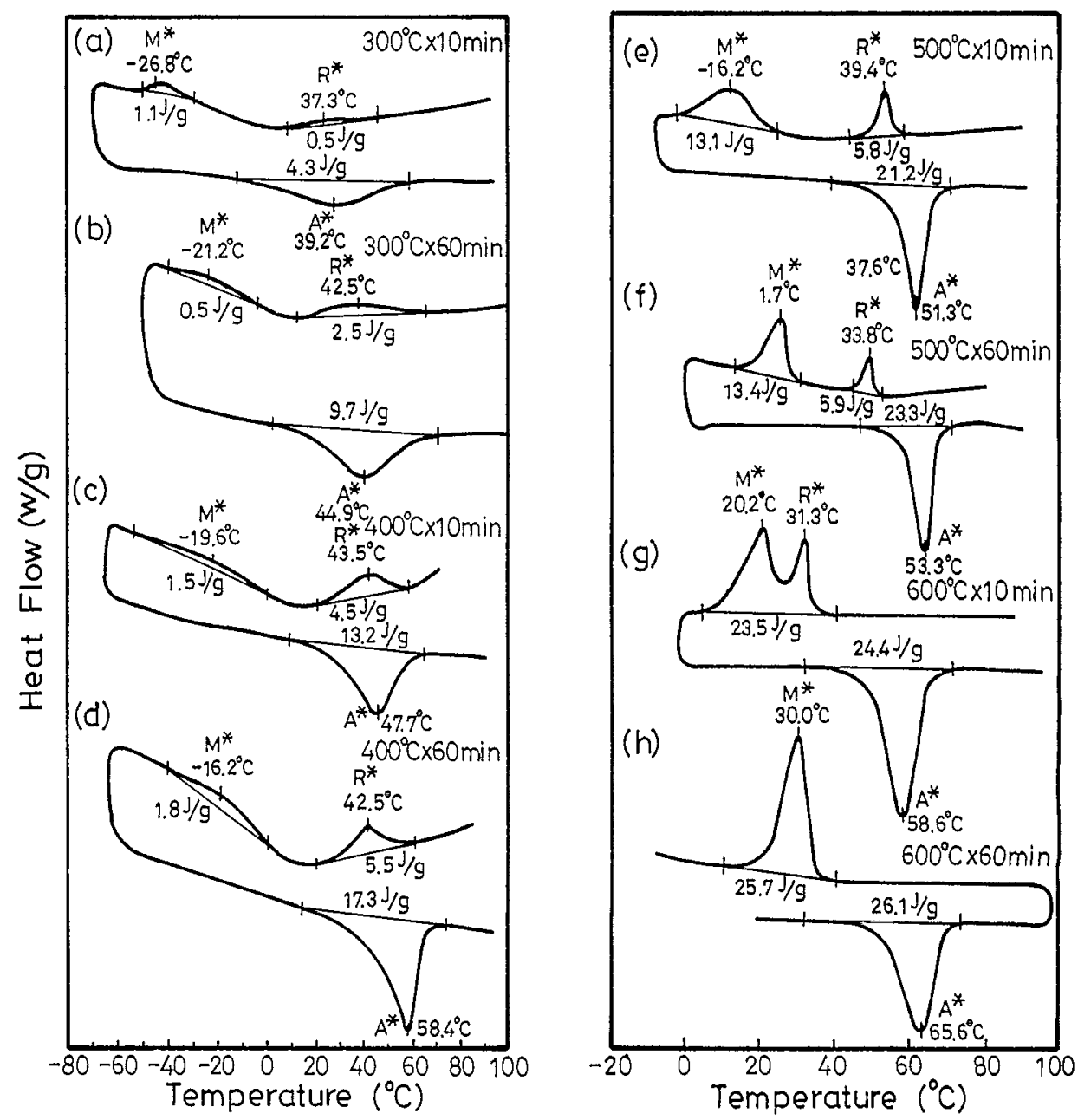

Fig. 4. Some typical DSC curves for drawn $\mathrm{Ti}_{50} \mathrm{Ni}_{50}$ wires with $26.5 \%$ cold-working and then annealing at various temperatures and time periods. (a) $300^{\circ} \mathrm{C} \times 10 \mathrm{~min}$, (b) $300^{\circ} \mathrm{C} \times 60 \mathrm{~min}$, (c) $400^{\circ} \mathrm{C} \times 10 \mathrm{~min}$, (d) $400^{\circ} \mathrm{C} \times 60 \mathrm{~min}$, (e) $500{ }^{\circ} \mathrm{C} \times 10 \mathrm{~min}$, (f) $500^{\circ} \mathrm{C} \times 60 \mathrm{~min}$, (g) $600^{\circ} \mathrm{C} \times 10$ min, (h) $600^{\circ} \mathrm{C} \times 60$ min. Noted that peaks R*, $M^{*}$ and $A^{*}$ represent B2 $\rightarrow$ R-phase transformation, R-phase $\rightarrow$ M19' martensitic transformation

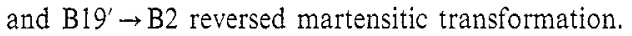

\subsection{The effects of oxide film on wire drawing}

Some studies have reported that the surface oxide film can be used as a lubricant during the TiNi wire drawing process $[6-8]$. In order to further understand the effects of oxide film on TiNi wire drawing, surfacecleaned and annealed $\mathrm{Ti}_{50} \mathrm{Ni}_{50}$ wires were heated in normal atmosphere at $550^{\circ} \mathrm{C}$ for different time periods to obtain different thickness of surface oxide film. The surface-cleaning and the subsequent annealing processes used in this study are as follows. $\mathrm{Ti}_{50} \mathrm{Ni}_{50}$ wires were first acid-cleaned ultrasonically in a solution of $\mathrm{HF}: \mathrm{HNO}_{3}: \mathrm{H}_{2} \mathrm{O}=1: 5: 20$ by volume ratio for $20 \mathrm{~min}$. The surface-cleaned $\mathrm{Ti}_{50} \mathrm{Ni}_{50}$ wires were then encapsulated in a quartz tube and evacuated to $10^{-6}$ torr, solution-treated at $850{ }^{\circ} \mathrm{C} \times 2 \mathrm{~h}$ and then waterquenched. After completion of the surface-cleaning and annealing processes, the $\mathrm{Ti}_{50} \mathrm{Ni}_{50}$ wires have a bright surface with unobservable surface oxide.

Fig. 7 shows the measured thicknesses of oxide films vs. heating time for surface-cleaned and annealed
$\mathrm{Ti}_{50} \mathrm{Ni}_{50}$ wires heated at $550{ }^{\circ} \mathrm{C}$ for various time periods. The thickness measurement is based on the SEM observations of oxidized specimens at $20000 \times$ [19]. The drawing stresses vs. different heating times at $14.3 \%$ cold work (from $\phi=0.81 \mathrm{~mm}$ to $\phi=0.75 \mathrm{~mm}$ ), i.e., under different thicknesses of oxidation film, are also shown in Fig. 7. As shown in Fig. 7, the drawing stress decreases sharply in the early 20 min of heating time and then maintains a low value, though the thickness of the oxide film monotonously increases with heating time. This indicates that a thin oxide film is sufficient for use as a lubricant during the drawing. In contrast, a thick oxide film will damage drawing properties. Fig. 8(a)-(c) show SEM observations of $80 \mu \mathrm{m} \phi$ fine TiNi wires after interannealing at $550^{\circ} \mathrm{C} \times 10 \mathrm{~min}$, $550^{\circ} \mathrm{C} \times 70 \mathrm{~min}$ and $700^{\circ} \mathrm{C} \times 10 \mathrm{~min}$, respectively. Fig. 8(a) shows a smooth surface and a thin oxide film, but Fig. 8(b) and (c) exhibit thick oxide films with cracks and spalling on the surfaces. These surface cracks and spalling only occur in thick films which have been identified as $\mathrm{TiO}_{2}$ [20]. Obviously, the thickness of 


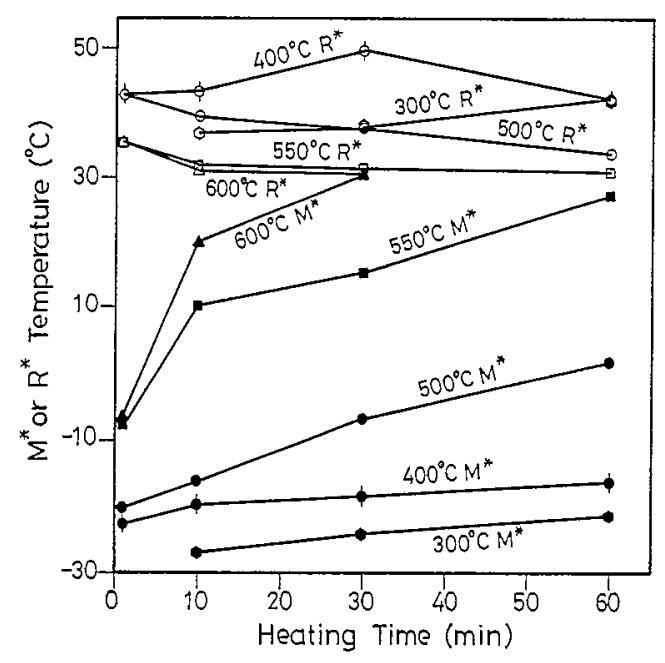

Fig. 5. $R^{*}$ and $M^{*}$ temperatures vs. annealing time for different annealing temperatures of $\mathrm{Ti}_{50} \mathrm{Ni}_{50}$ wires. The wires' degree of cold work is $26.5 \%$.

oxide film increases with higher annealing temperatures and longer annealing time periods. In this study, the heating/interannealing condition of $550^{\circ} \mathrm{C} \times 10 \mathrm{~min}$ in atmosphere results in a thickness of oxide film adequate to serve as a lubricant and TiNi wires can be drawn to below $30 \mu \mathrm{m} \phi$ under this heating/interannealing condition. It is not possible to draw to ultrafine wires from wires with a thick oxide layer owing to the detrimental effects of thick oxide on the wire's surface quality which easily causes the wires to break.

Another disadvantage of the thick oxide film formed on TiNi wires is that it can depress TiNi SMAs' shape memory effect and pseudoelasticity. One example is shown in Fig. 9 in which the pseudoelasticity behavior of $700^{\circ} \mathrm{C} \times 10 \mathrm{~min}$ interannealed $\mathrm{Ti}_{49} \mathrm{Ni}_{51} 50 \mu \mathrm{m} \phi$ wire is plotted. The pseudoelasticity of this fine wire is worse ( $<40 \%$ recovery for the $8 \%$ strain) than the $\mathrm{Ti}_{49} \mathrm{Ni}_{51}$ bulk specimen [3]. Two factors might be responsible for

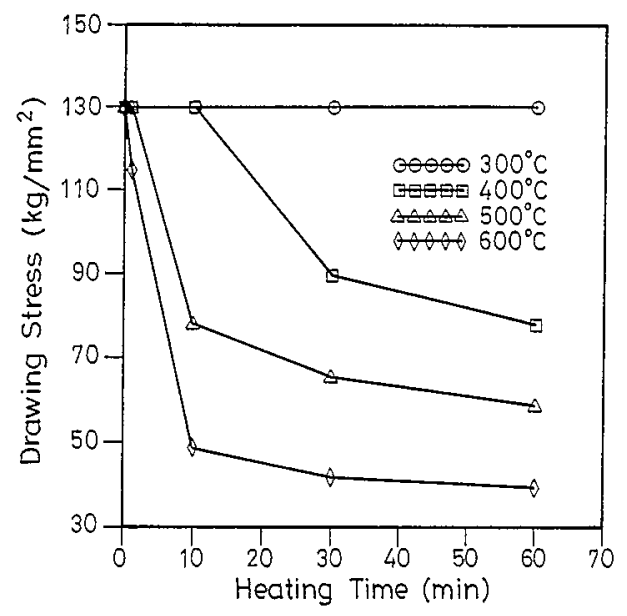

Fig. 6. The drawing stress at $10.43 \%$ cold work for the $26.5 \%$ pre-drawn $\mathrm{Ti}_{50} \mathrm{Ni}_{50}$ wires interannealed at various temperatures and time periods.

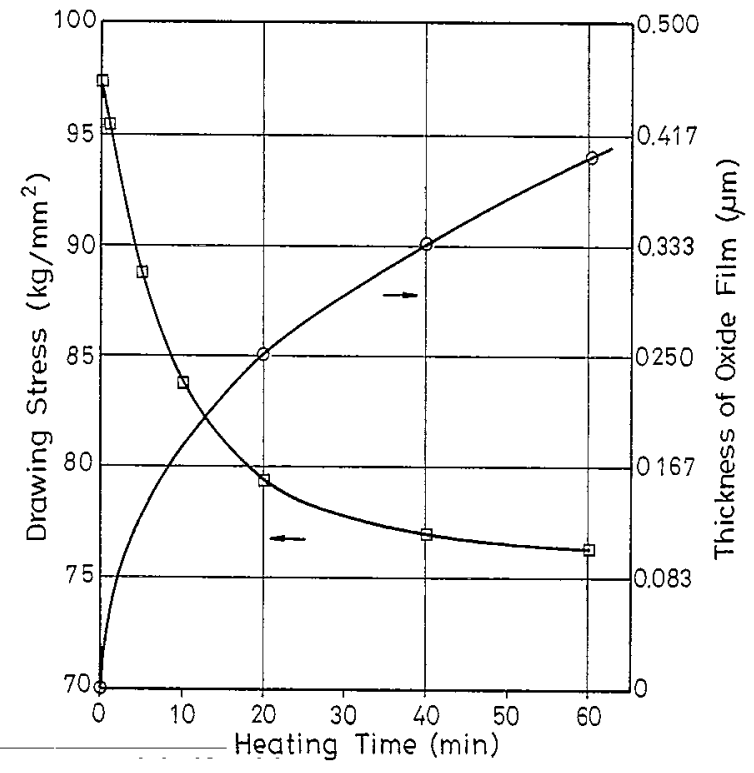

Fig. 7. The measured thickness of oxide film and the drawing stress vs. heating time at $550{ }^{\circ} \mathrm{C}$ for $\mathrm{Ti}_{50} \mathrm{Ni}_{50}$ wires. The wires' degree of cold work is $14.3 \%$.

this feature. First, the $\mathrm{TiO}_{2}$ oxide film at the surface does not exhibit the shape memory effect and pseudoelasticity. Second, the introduction of oxygen atoms at the subsurface can depress the martensitic transformation to a lower temperature [16], and hence the $M_{\mathrm{d}}$ - temperature near the $\mathrm{Ti}_{49} \mathrm{Ni}_{51}$ wire surface may be lower than room temperature. Here, $M_{\mathrm{d}}$ is a temperature above the $M_{\mathrm{s}}$, and for temperatures between $M_{\mathrm{d}}$ and $M_{s}$, TiNi SMAs can exhibit the pseudoelasticity. Therefore, the pseudoelastic behavior tested at room temperature is worse because a lower volume of stress-- induced martensite can occur in the whole wire. Hence, the oxide film should be removed to improve the shape memory effect and pseudoelasticity after the drawing process has been completed.

\subsection{The effects of lubricants on the wire drawing}

In order to understand the effects of lubricants on the wire drawing, the lubricants $\mathrm{MoS}_{2}$, oil and soap were used in a three-pass drawing. Fig. 10 shows the drawing stress vs. degree of cold work for $\mathrm{Ti}_{50} \mathrm{Ni}_{50}$ wires during the three-pass drawing $(13.61 \% \rightarrow$ $17.94 \% \rightarrow 22.15 \%$ ). In Fig. 10, for all four tested $\mathrm{Ti}_{50} \mathrm{Ni}_{50}$ wires tested with or without lubricant, the drawing stresses in the first pass have nearly the same values. However, in the second and third passes, drawing stresses were quite different, namely, $\mathrm{MoS}_{2}<$ oil $<$ soap $<$ none. The results can be explained as follows. In this study, before wire drawing, a thin oxide film was formed on the stress-relieved $\mathrm{Ti}_{50} \mathrm{Ni}_{50}$ wires by heating at $550^{\circ} \mathrm{C}$ for $10 \mathrm{~min}$. The oxide films exhibit important lubricating effects during the first-pass drawing, 
whether the wire surface has lubricant or not. Hence, the drawing stresses for all of the tested $\mathrm{Ti}_{50} \mathrm{Ni}_{50}$ wires of Fig. 10 have nearly the same values. However, oxide films are destroyed or thinned after the first-pass drawing and thereafter resulting in a lower lubrication by the oxide films in the further drawings. Therefore, the lubricants $\mathrm{MoS}_{2}$, oil and soap plays an important role during the second and third pass drawings and the drawing stress with lubricant is comparably lower than that without lubricant. Among these lubricants, $\mathrm{MoS}_{2}$ seems to be the most effective because the drawing stress with $\mathrm{MoS}_{2}$ lubricant is the lowest in Fig. 10. In addition, $\mathrm{MoS}_{2}$ lubricant is a Newtonian fluid, namely,
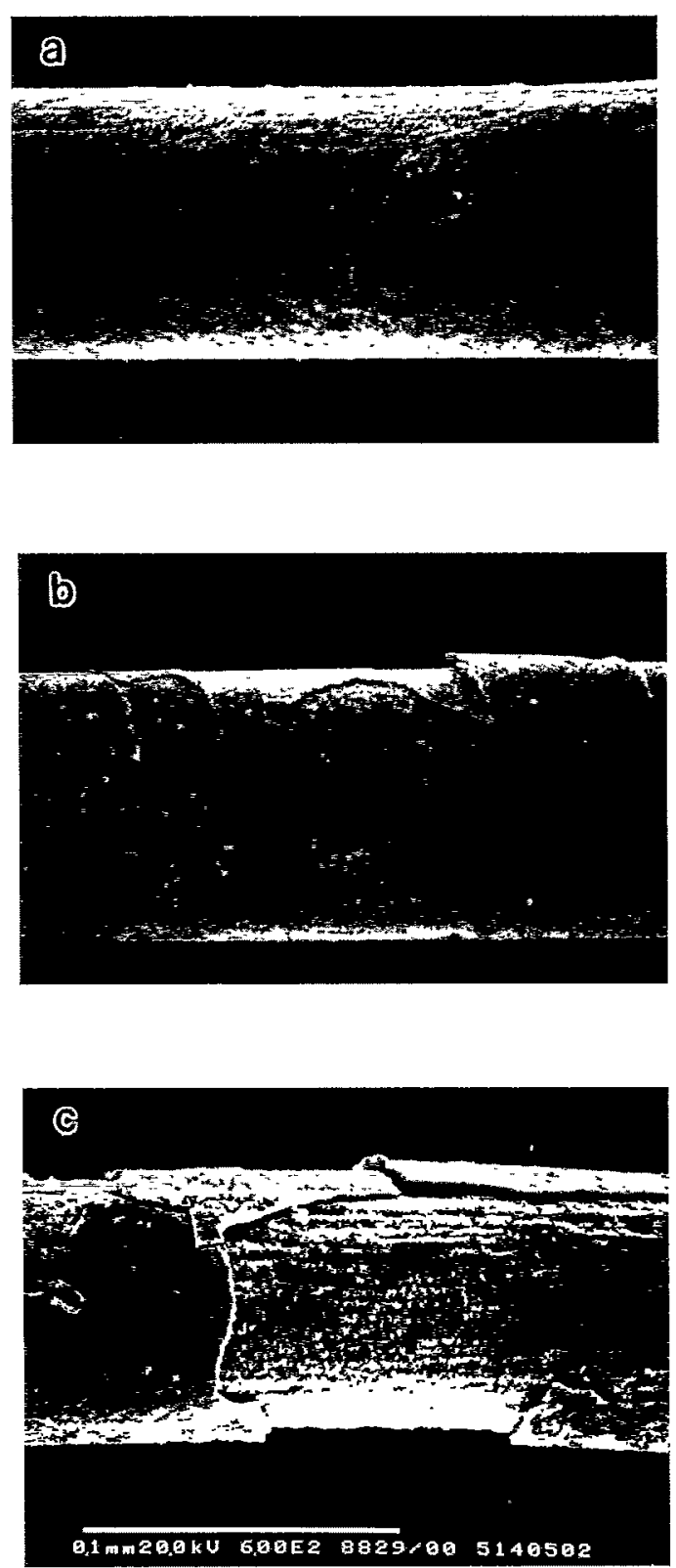

Fig. 8. The SEM observations of $80 \mu \mathrm{m} \phi$ fine TiNi wires after interamnealing at (a) $550^{\circ} \mathrm{C} \times 10 \mathrm{~min}$, (b) $550^{\circ} \mathrm{C} \times 70 \mathrm{~min}$, and (c) $700^{\circ} \mathrm{C} \times 10 \mathrm{~min}$ respectively.

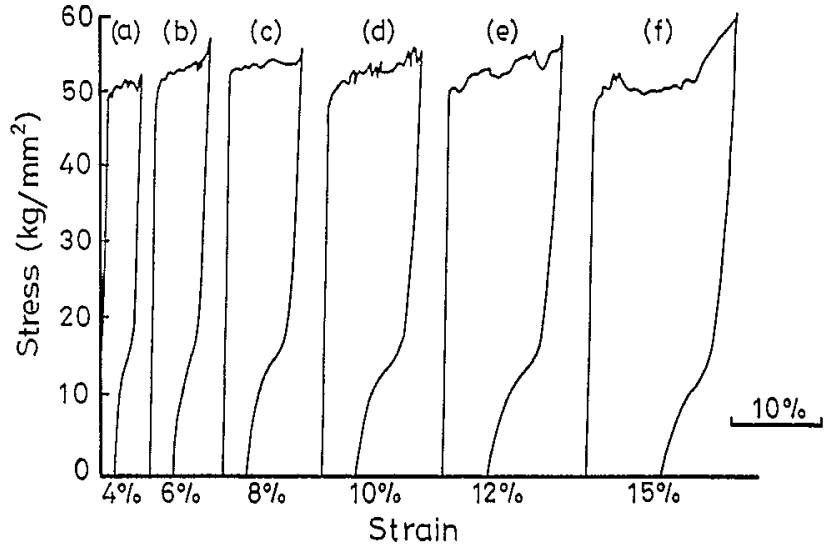

Fig. 9. The pseudoelastic behavior of $700^{\circ} \mathrm{C} \times 10 \mathrm{~min}$ interannealed $\mathrm{Ti}_{49} \mathrm{Ni}_{51}$ wire. The diameter of the wire is $50 \mu \mathrm{m}$. The tensile strain is (a) $4 \%$, (b) $6 \%$, (c) $8 \%$, (d) $10 \%$, (e) $12 \%$ and (f) $15 \%$. The strain rate is $50 \mathrm{~mm} \mathrm{~min}^{-1}$.

its viscosity coefficient is independent of flow rate [19]. This feature can increase drawing stability and promote the drawn wire quality.

\section{Conclusions}

(i) The inherently severe work hardening properties in TiNi SMAs depress their drawing properties and interannealing is necessary. A multi-pass drawing at around the $M_{s}$ temperature of TiNi SMAs is recommended.

(ii) Thin oxide film with a smooth surface on TiNi wires can be used as a lubricant during the drawing

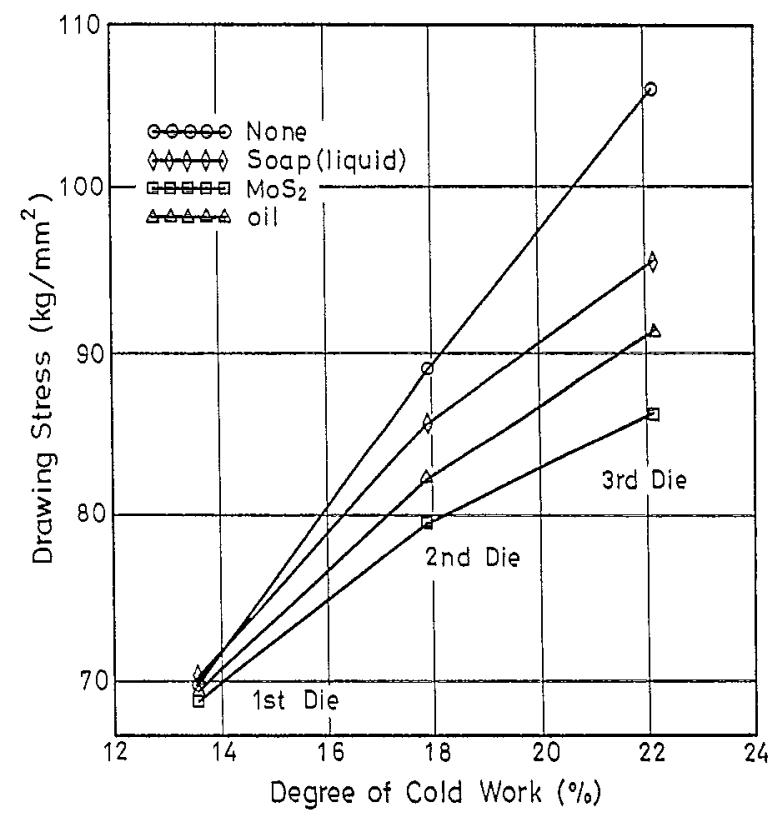

Fig. 10. The drawing stress vs, the degree of cold work for $\mathrm{Ti}_{50} \mathrm{Ni}_{50}$ wires with or without lubricant. The lubricants used in the three-pass drawing are $\mathrm{MoS}_{2}$, oil, and soap. The degrees of cold work are first die $13.61 \%$, second die $17.94 \%$ and third die $22.15 \%$ 
process. However, thick oxide films which have cracks and spalling on the surface can be detrimental to the drawing surface and depress the shape memory effect and pseudoelasticity of TiNi SMAs.

(iii) $\mathrm{MoS}_{2}$ is an effective lubricant for wire drawing of TiNi SMAs.

\section{Acknowledgements}

The authors are pleased to acknowledge the financial support of this research by Tjing Ling Industrial Research Institute, National Taiwan University, under Grants 82-G-10 and 83-G-10, and by National Science Council (NSC), Republic of China, under Grant NSC83-0405-E002-011.

\section{References}

[1] S. Miyazaki, K. Otsuka and Y. Suzuki, Scr. Metall., 15 (1987) 287.

[2] S. Miyazaki, Y. Ohmi, K. Otsuka and Y. Suzuki, J. Phys., 43 (1982) C4-255.

[3] S. Miyazaki, T. Imai, Y. Igo and K. Otsuka, Metall. Trans., $17 A$ (1986) 115.

[4] H.C. Lin, S.K. Wu and M.T. Yeh, Metall. Trans., 24A (1993) 2189.
[5] H.C. Lin, S.K. Wu and Y.C. Chang, Metall. Trans., 26A (1995).

[6] C.M. Jackson, H.J. Wagner and R.J. Wasilewski, NASASP5110 (1972) 19.

[7] W.J. Buehler and W.B. Cross, Wire J., June (1969) 41.

[8] M. Aiba, H. Nagai and M. Asakawa, Mater. Jpn., JIM, 31 (6) (1992) 541 (In Japanese).

[9] K. Yoshida and H. Tanaka, Wire, 45 (1995) 2.

[10] Y. Kawaguchi, K. Katsube, M. Murahashi, Y. Yamada, Wire J., 12 (1992) 53.

[11] S. Saito, T. Wachi and S. Hanada, Mater. Sci. Eng., Al61 (1993) 91.

[12] Y. Liu and P.G. McCormick, Acta Metall. Mater., 38 (1990) 1321.

[13] Y. Liu and P.G. McCormick, ISIJ, 29 (1989) 417.

[14] P.E. Thoma, M.Y. Kao, S. Fariabi and D.N. Abujudom, ICOMAT (1992) 917.

[15] H.C. Lin, S.K. Wu and Y.C. Yen, Proc. PRICM-2, Kyongju, Korea, 1995, in press.

[16] H. Funakubo, Shape Memory Alloys, translated by J.B. Kennedy, Gordon and Breach Science, New York, 1984, Ch. 2.

[17] Z. Nishiyama, Martensitic Transformation, Academic Press, New York, 1978, Ch. 3.

[18] A.I. Lotkov, A.V. Kuznetsov, V.N. Griskov and A.A. Botaki, in Y. Chu, T.Y. Hsu and T. Ko (eds.), Proc. Int. Shape Memory Alloy Symp., Guilin, China, 1986, p. 153.

[19] J.C. Chen, Master Thesis, Department of Mechanical Engineering, National Taiwan University, 1995.

[20] C.L. Chu and S.K. Wu and Y.C. Yen, Mater. Sci. Eng. A, (1996) in press.

[21] H.C. Lin, S.W. Wu, T.S. Chou and H.P. Kao, Acta Metall. Mater., 39 (1991) 2069.

[22] H.C. Lin and S.K. We, Mater. Sci. Eng., A158 (1992) 87. 